\title{
AUTONOMÍA DE LA VOLUNTAD Y LAS PERSPECTIVAS ACTUALES DEL
}

\section{ARBITRAJE EN BRASIL ${ }^{1}$}

\section{AUTONOMY OF THE WILL AND CURRENT PERSPECTIVES OF ARBITRATION}

\section{IN BRAZIL}

Bernardo Baccon Gehlen Graduado en Derecho en la Universidad de Santa Cruz do Sul - UNISC y miembro de la Cámara de Arbitraje de la Asociación de Comercio e Industria de Santa Cruz do Sul. Originario de Passo Fundo, Rio Grande do Sul, Brasil. Currículo Lattes: http://lattes.cnpq.br/3060144142573138. Santa Cruz do Sul/RS. E-mail: begehlen@gmail.com

Fabiana Marion Spengler Bolsista de Productividad en Investigación del CNPq (Pq2). Postdoctorado en Derecho por la Università degli Studi di Roma Tre, en Roma, Italia, con beca CNPq (PDE). Doctora en Derecho por el programa de Posgrado stricto sensu de la Universidad del Vale do Rio dos Sinos - UNISINOS - RS, con beca Capes, Maestría en Desarrollo Regional, con concentración en el área de Política Institucional de la Universidad de Santa Cruz do Sul - UNISC - RS, profesora de los cursos de Licenciatura y Posgrado lato e stricto sensu de la UNISC, Coordinadora del Grupo de Investigación "Políticas Públicas en el Tratamiento de Conflictos" vinculado al CNPq; coordinadora del proyecto de investigación "El tercero y el conflicto: el mediador, el conciliador, el juez, el árbitro y sus roles políticos y sociales" financiado por la Fundación de Apoyo a la Investigación del

\footnotetext{
${ }^{1}$ Artigo recebido em 10/02/2021 e aprovado em 04/06/2021.
} 
Estado del Rio Grande do Sul - Fapergs, Edicto 02/2017 $\mathrm{PqG}$ - Investigadora Gaúcha, coordinadora y mediadora del proyecto de extensión: "La crisis de la jurisdicción y la cultura de la paz: la mediación como medio democrático, autónomo y consensuado de tratar los conflictos" financiado por la Universidad de Santa Cruz do Sul - UNISC; autora de varios libros y artículos científicos, e-mail: fabiana@unisc.br, link currículo Lattes: http://lattes.cnpq.br/8254613355102364. Master en Derecho por la Universidad de Santa Cruz do Sul (UNISC), donde actualmente es profesor asistente. Profesor de Derecho Procesal Civil (Proceso de Conocimiento, Proceso de Ejecución, Procedimientos Especiales), Mediación y Arbitraje y Derecho Civil - Responsabilidad Civil. Vicedirector del Grupo de Investigación "Políticas Públicas en el tratamiento de conflictos", certificado por el CNPq, dirigido por la Prof. Fabiana Marion Spengler. Socio de Spengler Advocacia Sociedade de Advogados y administrador de Essere nel Mondo Editora Ltda. Abogado. Asesor legal. Originaria de Santa Cruz do Sul, Rio Grande do Sul, Brasil. Santa Cruz do Sul/RS. E-mail: fabianaspengler@spengleradvocatio.com.br.

Theobaldo Spengler Neto Máster en Derecho por la Universidad de Santa Cruz do Sul (UNISC), donde actualmente es profesor asistente. Profesor de Derecho Procesal Civil (Proceso de Conocimiento, Proceso de Ejecución, Procedimientos Especiales), Mediación y Arbitraje y Derecho Civil - Responsabilidad Civil. Vicedirector del Grupo de Investigación "Políticas Públicas en el tratamiento de conflictos", certificado por el 
CNPq, dirigido por la Prof. Fabiana Marion Spengler. Socio de Spengler Advocacia Sociedade de Advogados y administrador de Essere nel Mondo Editora Ltda. Abogado. Asesor legal. Originário de Santa Cruz do Sul, Rio Grande do Sul. E-mail: theobaldospengler@spengleradvocatio.com.br.

RESUMEN: El tema central de este texto es el análisis del principio de la autonomía de la voluntad contractual como factor decisivo para el funcionamiento y seguridad jurídica del instituto del arbitraje en Brasil. A través del método deductivo, fueron examinadas las recientes leyes y jurisprudencias de los tribunales brasileños que salvaguardan (o no) lo acordado en detrimento del interés colectivo y derechos indisponibles. Se concluye que excepto en las relaciones de consumo - las cláusulas compromisorias tienen fuerza vinculante, mismo cuando enfrentan cuestiones de orden público o de comprobada vulnerabilidad de una de las partes contratantes.

PALABRAS CLAVE: Arbitraje; autonomía de la voluntad; cláusula compromisoria; orden público; contrato mercantil.

ABSTRACT: The main argument of this text is the analysis of the principle of party autonomy on contracts as a decisive factor for the operation and legal certainty of the arbitration institute in Brazil. Recent laws and jurisprudence from Brazilian courts, which safeguard (or not) the agreement between parties in detriment of collective interest and unalienable rights, have been investigated through the deductive method. It is possible to conclude that - except in cases ruled by customer law - arbitration clauses set forth by the parties are binding, even when opposing public order or proven vulnerability of one of the contracting parties.

KEYWORDS: Arbitration; party autonomy; arbitration clause; public policy; commercial contract. 


\section{CONSIDERACIONES INICIALES}

El acceso a la justicia como derecho fundamental y elemento indispensable en la evolución del sistema judicial se ha ido consolidando progresivamente a través de medios alternativos de resolución de conflictos, especialmente con el instituto de arbitraje. A pesar de cierto escepticismo ante la suya legitimidad y carácter jurisdiccional, la búsqueda de una solución rápida y menos estresante para las partes ha hecho que el instituto sea una realidad en el territorio brasileño, especialmente en la esfera empresarial y de los negocios.

El principio de la autonomía de la voluntad, como guía de las relaciones contractuales en el derecho interno y pilar de la búsqueda de la seguridad jurídica y la previsibilidad en las relaciones jurídicas, se ha puesto de manifiesto en la mayoría de los cambios legislativos recientes. De la misma manera, el principio ha demostrado ser fundamental para el uso del arbitraje en el Brasil, inicialmente como condición para la existencia del instituto a partir de una elección hecha por las partes contratantes, más tarde como la posibilidad de elección del número de árbitros, normas de derecho o equidad, formas de procedimiento, etc., y finalmente como justificación de las decisiones de los tribunales para salvaguardar lo que ha sido acordado por las partes involucradas.

El objetivo principal de este texto se desarrolla en ese último aspecto: el análisis de aplicación del principio de la autonomía de la voluntad en situaciones fácticas y en las recientes decisiones del Tribunal Superior de Justicia como forma de justificar e salvaguardar lo acordado por las partes, dando así seguridad jurídica al uso de arbitraje.

Para cumplir con el propósito se utilizará el método deductivo a través del análisis doctrinal, jurisprudencial y utilización de la legislación pura. Inicialmente, se examina el principio de la autonomía de la voluntad tanto en las relaciones contractuales de derecho interno, su apreciación en los contratos de consumo y de negocios y sus particularidades de aplicación en el arbitraje. En segundo lugar, se abordarán decisiones importantes que han puesto los jueces en una delgada línea al decidir entre los asuntos de orden público y/o la reconocida vulnerabilidad de una de las partes contratantes y la competencia del árbitro para analizar de antemano los temas que se le plateen a través de la cláusula compromisoria. 


\section{EL ACCESO A LA JUSTICIA Y LAS ALTERNATIVAS DE SOLUCIÓN DE CONTROVERSIAS EN EL BRASIL}

El Estado democrático de derecho, como expresión jurídica de la democracia, basada principalmente en la soberanía popular y en la garantía de los derechos y libertades fundamentales, es el principal agente de la aplicación de los instrumentos de regulación de la sociedad. De igual manera, es el motor y responsable de vigilar los movimientos evolutivos de la sociedad, de la adaptación y del compromiso con las propuestas progresivas que garanticen, en el ámbito jurídico, la preservación de los fundamentos democráticos y la efectividad de la tutela jurisdiccional ${ }^{2}$.

El movimiento de acceso a la justicia como un derecho fundamental que se produjo desde la Constitución Federal de 1988 debe ser visto, por lo consiguiente, como un elemento indispensable en la evolución del sistema judicial, necesario para la supervivencia del proceso de transformación socioeconómica, política y cultural, como una forma de incorporar los problemas y demandas sociales. El movimiento de acceso a la justicia que se intensificó a partir de los años 90 se reveló, sobre todo, un enfoque social frente a los problemas que enfrenta el hombre contemporáneo, reflejo de un modelo económico hegemónico del mundo capitalista, en una época en la que el consumo y la explotación se convirtieron en fenómenos de masas ${ }^{3}$.

Modificaciones en el texto constitucional como expresión del Estado en la tutela de los derechos difusos y colectivos, como forma de aproximar el ciudadano del poder judicial y ampliar los polos procesales, empezaran por la "Ação popular" (art. 5 LXXIII de la CF), la Acción Civil Pública (Leyes 7.347/85 y 7.913/89), el Mandato de Seguridad (Art. 5, LXX), el Código de Defensa del Consumidor ${ }^{5}$ y la institución de los "Juizados Especiais

\footnotetext{
${ }^{2}$ AYOUB, Luiz Roberto. Arbitragem: o acesso à justiça e a eficacia do processo - uma nova proposta -. Río de Janeiro: Editora Lemen Juris, 2015.

${ }^{3}$ AYOUB, Luiz Roberto. Arbitragem: o acesso à justiça e a eficacia do processo - uma nova proposta -. Río de Janeiro: Editora Lemen Juris, 2015.

4 "Ações populares" (trad. en español = Acciones Populares) son acciones que permiten al ciudadano una respuesta para la protección de derechos colectivos contra actos administrativos potencialmente inidóneos y/o inmorales.

${ }^{5}$ BRASIL. Lei $n^{\circ}$ 8.078, de 11 de setembro de 1990. Código de defesa e proteção ao consumidor e outras disposições. Disponible en: http://www.planalto.gov.br/ccivil_03/Leis/L8078.htm. Acceso el 26 de enero de 2020
} 
Cíveis" ${ }^{\prime 6}$ (Ley 9.099/95), se coordinaron para superar las barreras y hacer accesible el sistema procesal $^{7}$.

Pese el acceso a la justicia ser un elemento fundamental en la evolución del poder judicial, el impulso legislativo generó consecuencias prácticas inesperadas y frustró las expectativas humanistas y democráticas del movimiento. El impulso tropezó con el obstáculo procesal, que no pocas veces comenzó a presentar una solución prolongada, trayendo más daño y angustia que beneficio y tranquilidad a las partes litigantes ${ }^{8}$.

Las encuestas realizadas por el Consejo Nacional de Justicia en el año de 2010 mostraron una tasa de congestión en el poder judicial brasileño del 71\%. Es decir, que de cada 100 casos que se tramitaron en el sistema de justicia brasileño en el año anterior, 71 quedaron sin resolución. En 2016 la tasa de congestión representaba el 73\% de los casos en curso, habiéndose reducido al $72 \%$ en $2017^{9}$. A pesar de la reducción de 1 punto porcentual ser la más alta registrada desde 2009, el elevado número de casos atascados y la consiguiente demora en la resolución de los conflictos, no atenuaron el descrédito en el proceso judicial.

Ocurre, todavía, que los fenómenos de globalización - que son el origen de políticas positivas de preservación de la autonomía y de la soberanía nacional - necesitan agilidad en los contratos y en sus relaciones jurídicas. Las nuevas orientaciones económicas de los países centrales, los descubrimientos tecnológicos y el espacio para los inversores en una economía sin fronteras han traído reflejos colectivos y han forzado al Estado al desbloqueo y la retirada del poder decisional sobre determinadas materias. El propio Estado asume una vez más la responsabilidad que le es peculiar y primordial: promover la justicia, respetando los principios y garantías fundamentales. Así, "los métodos existentes desde el principio de la humanidad, como la mediación, la conciliación y el arbitraje, están resurgiendo como una forma de mejora y como soluciones alternativas a la disposición jurisdiccional" 10 .

\footnotetext{
6 "Juizados Especiais Cíveis" (trad. en español = "Juzgados Especiales Civiles") son órganos de la justicia ordinaria brasileña para conciliación, proceso, juicio y ejecución en las causas de menor complejidad cuyo valor no exceda cuarenta salarios mínimos.

${ }^{7}$ MORAIS, J. L. B.; SPENGLER, F. M. Mediação e arbitragem. Alternativas à jurisdição. Porto Alegre: Livraria do Advogado, 2019, v.1.

${ }^{8}$ AYOUB, Luiz Roberto. Arbitragem: o acesso à justiça e a eficacia do processo - uma nova proposta -. Río de Janeiro: Editora Lemen Juris, 2005.

${ }^{9}$ BRASIL. Congestionamento do Judiciário cai para 72\% em 2017. Conselho Nacional de Justiça, 2018. Disponible en: https://www.cnj.jus.br/congestionamento-do-judiciario-cai-para-72-em-2017/.

${ }^{10}$ AYOUB, Luiz Roberto. Arbitragem: o acesso à justiça e a eficacia do processo - uma nova proposta -. Río de Janeiro: Editora Lemen Juris, 2005.
} 
El procedimiento de arbitraje, permitido desde el período colonial en el Brasil, regulado anteriormente por las Ordenanzas Filipinas, que a lo largo del siglo tendrían alternado entre el compromiso obligatorio y el voluntario ${ }^{11}$, se recupera y se consolida con el advenimiento de la Ley de Arbitraje ${ }^{12}$, que reforzó la competencia del tribunal de arbitraje excluyendo de la jurisdicción estatal el poder de resolver el conflicto sobre determinadas materias $^{13}$.

La Ley de Arbitraje, "consagrando la autonomía de la voluntad" dio eficacia a la cláusula compromisoria, eliminó la necesidad de homologación del laudo arbitral, disciplinó la homologación de una sentencia extranjera en el Tribunal Supremo Federal y reforzó la búsqueda de la imparcialidad del árbitro, puesto que previó su sospecha e impedimento. A pesar de la falta de aplicabilidad y de coerción, el escepticismo en cuanto a la naturaleza judicial del instituto ya se puede considerar anticuado ${ }^{14}$.

Además, las alegaciones de que el instituto de arbitraje es primitivo, regresivo a los momentos preestatales, anarquista y precursor del alto capitalismo, destinado a la protección del capital internacional, hacen del argumento una asociación equivocada de su utilización. Las polémicas y la desconfianza en los medios alternativos de resolución de conflictos, sobretodo el arbitraje son "aguas pasadas", ya que, "gradual y lentamente, los contratos comerciales y los contratos corporativos comenzaron a incorporar cláusulas compromisorias $^{15}$ ".

\subsection{PANORAMA ACTUAL DE LA UTILIZACIÓN DEL ARBITRAJE}

Aunque por razones culturales la sociedad brasileña demuestra timidez en el uso del arbitraje, en el año 2015 el país ya era el líder en su utilización entre los países sudamericanos

\footnotetext{
${ }^{11}$ El advenimiento de la Ley 1350/1866 que revocó la obligatoriedad del arbitraje para las reclamaciones de las empresas, el Código Civil de 1916, el Código de Procedimiento Civil de 1936 y 1973 que redujo el arbitraje a un mero compromiso, haciéndolo opcional. (SPENGLER; SPENGLER NETO, 2016, p. 179)

12 BRASIL. Lei 9.307 de 1996. Lei da arbitragem. Diário Oficial da República Federativa do Brasil Gaceta Oficial de la República Federativa del Brasil, Brasilia, DF, 23 de setembro de 1996. Disponible en: <http://www.planalto.gov.br/ccivil_03/leis/19307.htm>. Acceso el 10 de febrero de 2020.

${ }^{13}$ SPENGLER, Fabiana; SPENGLER NETO, Theobaldo (org). Mediação, conciliação e arbtiragem. Rio de Janeiro: Editora FGV, 2016.

${ }^{14}$ AYOUB, Luiz Roberto. Arbitragem: o acesso à justiça e a eficacia do processo - uma nova proposta - Río de Janeiro: Editora Lemen Juris, 2005.

${ }^{15}$ CARMONA, Carlos Alberto. Arbitragem e procedimento - comentários sobre a lei 9.307/96. Río de Janeiro: Editorial Atlas, 2004.
} 
y el cuarto puesto en el ranking mundial. Durante el mismo período, según el "Conselho Nacional das Instituições de Mediação e Arbitragem", creado por el Colegio de Abogados de Brasil, el número de cámaras de arbitraje fue de cerca de 100, además de varios cursos, conferencias, seminarios, congresos, etc. que han venido fomentando el debate y la difusión del instituto ${ }^{16}$.

Para Spengler y Morais ${ }^{17}$ el actual panorama político y legislativo del Brasil se ha mostrado favorable a la ampliación del uso de la jurisdicción paraestatal. La Ley 13.129/2015 procuró fortalecer el tribunal de arbitraje, mediante expresiones tales como vigorizar, reactivar y renacer, a fin de contribuir a la evolución del instituto. Asimismo, pretendió ser una fuerza motriz en las controversias que afectan la Administración Pública, entidades federales de administración directa o indirecta ${ }^{18}$.

Además, el legislador ha reforzado el principio de la fuerza de voluntad como guía de las relaciones contractuales y como base fundamental para el arbitraje, a fin de dar seguridad jurídica y previsibilidad a las partes. Los cambios recientes que refuerzan la libertad de las partes pueden verificarse en el nuevo Código de Procedimiento Civil (Ley 13.105/15), que admitió la legalidad en la estipulación de cambios en el procedimiento judicial, permitiendo a las partes ajustarlo a la causa y acordar sus cargas, facultades y deberes procesales, antes o durante el proceso.

La medida provisional 881, que se convertiría en la Ley de Libertad Económica de 2019 (LLE), precisamente en la subsección V de la exposición de motivos, expuso la preocupación del legislador por preservar la autonomía de la voluntad de las partes en las relaciones contractuales, considerándola como "una premisa del estado de derecho ${ }^{19}{ }^{\prime}$. La LLE modificaría los artículos 113 y 421 del Código Civil con el fin de preservar el pacta sunt servanda, especialmente en las relaciones contractuales civiles y comerciales, reacondicionando progresivamente la presunción de simetría entre las partes contratantes en el marco de la legislación general.

\footnotetext{
${ }^{16}$ CAHALI, Francisco José. Curso de arbitragem. $5^{\mathrm{a}}$ ed. São Paulo: Revista dos Tribunais, 2015.

${ }^{17}$ MORAIS, J. L. B.; SPENGLER, F. M. Mediação e arbitragem. Alternativas à jurisdição. Porto Alegre: Livraria do Advogado, 2019, v.1

${ }^{18}$ CAHALI, Francisco José. Curso de arbitragem. $3^{\mathrm{a}}$ ed. São Paulo: Revista dos Tribunais, 2013.

${ }^{19}$ BRASIL. Medida provisória 881 de 11 de abril de 2019. Congresso Nacional, Brasilia, DF. Disponible en: < http://www.planalto.gov.br/ccivil_03/_Ato2019-2022/2019/Exm/Exm-MP-881-19.pdf >. Acceso el 2 de febrero de 2020 .
} 
La más reciente modificación legislativa, con la Ley 13.966/2019, que prevé sobre el sistema de franquicia comercial, puntualmente en el artículo $7 \S 1$, indica que las partes pueden elegir un tribunal de arbitraje para resolver las controversias relacionadas con el contrato de franquicia, visiblemente como una forma de promover el uso de la solución paraestatal $^{20}$.

Pese el interés legislativo, es el poder judicial que tiene que evaluar la aplicabilidad de las normas según los casos concretos. Por lo tanto, la búsqueda progresiva de la libertad y de una mayor autonomía de las partes contratantes que confronto con cuestiones de orden público o relaciones entre sujetos privados desiguales, hace que el poder judicial sea un elemento decisivo en la utilización y el apoyo del instituto de arbitraje. En este sentido, es fundamental el estudio del principio de la autonomía de la voluntad de las partes y su aplicación según la naturaleza de la relación contractual.

\section{PRINCIPIO DE LA AUTONOMÍA DE LA VOLUNTAD EN LAS RELACIONES CONTRACTUALES BRASILENÃS}

La autonomía de la voluntad en el derecho interno brasileño, como principio de la teoría general de los contratos, comenzó a reeditarse la conformidad con las enmiendas introducidas por la Constitución Federal de 1988 que, a partir del nuevo orden mundial contemporáneo, puso de relieve los derechos fundamentales de la persona con el objetivo de garantizar la igualdad material, tanto en la relación entre el Estado y los particulares como en las relaciones puramente privadas. Los conceptos individualistas que anteriormente regían los negocios jurídicos se relativizaron por su función en temas de interés social y público $^{21}$.

El principio de que en el contrato clásico anterior se caracterizaría por la representación del sujeto que contrata si quiere, con quien quiere y en la forma que quiere, habiéndose reconocido los derechos y deberes de libre manifestación de la voluntad y la

\footnotetext{
${ }^{20}$ BRASIL. Lei $n^{\circ}$ 13.966, de 26 de dezembro de 2019. Dispõe sobre o sistema de franquia comercial e revoga a lei $\mathrm{N}^{\circ} 8.955$ de 15 de dezembro de 1994 (Ley de Franquias). Disponible en: <http://www.planalto.gov.br/ccivil_03/_Ato2019-2022/2019/Lei/L13966.htm\#art9>. Acceso el 11 de febrero de 2020.

${ }^{21}$ REIS, Jorge Renato. A função social do contrato e sua efetiva vinculação com as partes contratantes. Santa Cruz do Sul: Revista do Direito, p. 109-139, 2001.
} 
eficacia y validez del contratado, se reedita en el molde contemporáneo, no sólo por la nomenclatura - que ahora se trata como autonomía privada - sino en función de las nuevas exigencias sociales y colectivas ${ }^{22}$.

Además, con el cambio en esto "eje interpretativo", se reconsideraron los límites impuestos a las partes. Si en la teoría clásica la autonomía de la voluntad se limitaba a la cuestión del orden público y las buenas costumbres, en la época contemporánea las partes deben observar los principios de la buena fe, la función social y las disposiciones presentes en la legislación específica.

En las relaciones entre sujetos privados desiguales, la libertad debe limitarse para garantizar la protección de otros derechos fundamentales y limitar la imposición de poderes. A este respecto, el legislador privado brasileño, mediante principios inherentes al derecho privado, como la buena fe, las buenas costumbres, la función social del contrato, así como mediante una legislación especial, limita la libertad de las partes para garantizar la equivalencia de las obligaciones asumidas. El juez también puede imponer limitaciones a la libertad cuando ello sea necesario para garantizar la observancia de otras normas fundamentales, incluida la propia libertad ${ }^{23}$.

Para Rizzardo ${ }^{24}$, "se ha introducido la función social del contrato, que lleva al interés público a prevalecer sobre el interés privado, para imponer el beneficio colectivo a expensas del meramente individual". La reinterpretación del contrato contemporáneo abriría las puertas a una intervención normativa sobre el contenido vinculante del contrato, estableciendo límites a la libertad a través de medidas de control, corrección y compensación material, recomendadas por el principio de justicia social.

Sin embargo, esta intervención resultaría más incisiva en los contratos de consumo y de adhesión en los que una de las partes se encuentra en una situación de vulnerabilidad, caracterizada no sólo por el desequilibrio financiero sino también por el nivel de información y cultura. Mientras tanto, se ha mitigado la Teoría Finalista en estos contractos. Actualmente,

\footnotetext{
${ }^{22}$ COELHO, Fábio Ulhoa. Curso de direito comercial v. III. 15 a ed. São Paulo: Editora Saraiva, 2014.

${ }^{23}$ REIS, J. R.; DICK, J. H. Direitos Fundamentais: delimitações da sua influência no Direito Privado. Santa Cruz do Sul: Revista do Direito, p. 7-40, 2006.

${ }^{24}$ RIZZARDO, Arnaldo. Contratos. $18^{\mathrm{a}}$ ed. Río de Janeiro: Ed. Forense, 2019.
} 
se determina, aunque de manera excepcional, la aplicación de las normas del Código de Protección al Consumidor a las relaciones mercantiles ${ }^{25}$.

Por consiguiente, aunque la relación contractual sea una relación mercantil, llevada a cabo por empresas o profesionales que adquieren bienes y servicios con fines de lucro, puede reconocerse la vulnerabilidad (consecuentemente las reglas protectoras) una vez que se ha verificado la necesidad de estos "consumidores intermediarios" del producto o servicio o el monopolio de suministro del productor del bien ${ }^{26} 27$.

Así, en los contratos de consumo o de adhesión en general y, excepcionalmente, en los contratos comerciales, se relativiza la autonomía de la voluntad de las partes, disponiendo al juez del Estado la facultad de intervenir de manera más incisiva en las relaciones privadas para declarar la nulidad de las cláusulas abusivas y restablecer el equilibrio contractual. Esta lógica debe ser considerada al analizar las cláusulas de arbitraje en las relaciones contractuales que instituyen el tribunal de arbitraje para resolver cualquier conflicto.

Todavía, por regla general, en los contratos mercantiles, aunque muchos han considerado que las alteraciones interpretativas del contracto contemporáneo intervenciones progresivas habrían destruido "el dogma de la plena libertad y la expresión de la voluntad como fundamento, con el tiempo se ha ido comprendiendo la percepción del contrato como instrumento de convivencia social".

Es innegable que, de todos los ámbitos del derecho, el mercantil se muestra como el escenario en el que la libertad económica adquiere mayores dimensiones. [...] Después del vendaval - y la superación del excesivo individualismo contractual del siglo XIX -, vemos que los contratos mercantiles siguen su lógica peculiar, posibilitando el flujo de las relaciones económicas y la interacción entre empresas ${ }^{28}$.

Por consiguiente, se observa que en los contratos de naturaleza mercantil la interpretación de los magistrados debe diferenciarse de las normas generales, puesto que tienen la función esencial de impedir que una de las partes se exima de las obligaciones

\footnotetext{
${ }^{25}$ GEHLEN, Bernardo Baccon. Princípio da autonomía da vontade nos contratos empresariais de direito nacional e internacional. Santa Cruz do Sul: UNISC, 2019. 57 f. Monografia. Curso de Graduação da Universidade de Santa Cruz do Sul, 2019.

${ }^{26}$ REsp 1195642/RJ, Ministra Nancy Andrighi, Tercera Clase, juzgado el 13/11/2012, DJe 21/11/2012

${ }^{27}$ ROSENVALD, Nelson; FARIAS, Cristiano Chaves. Curso de direito civil 4: contratos, teoría geral dos contratos em espécie. São Paulo: Editora Atlas, 2015.

${ }^{28}$ FORGIONI, Paula. Teoria geral dos contratos empresariais. São Paulo: Revista dos Tribunais, 2018.
} 
acordadas y se libere del vínculo establecido entre ellas. "La obligatoriedad de los contratos hace posible la existencia del mercado, frenando el oportunismo indeseable de las empresas". Por lo tanto, si los contratos de una legislación específica (especialmente los contratos de consumo) se basan en la presunción de asimetría entre las partes, en los contratos mercantiles existe una tendencia a mantener la autonomía privada, lo que exige que los jueces respeten lo acordado para dar seguridad jurídica y previsibilidad al mercado ${ }^{29}$.

Es justamente por esa naturaleza jurídica que el juez debe prestar mayor atención al analizar la fuerza vinculante de la elección por cláusula compromisoria. Si en una relación mercantil se presume que las partes son simétricas, se presume, consecuentemente, que pudieron discutir las cláusulas contractuales y comprender claramente los riesgos del negocio jurídico y de la propia jurisdicción paraestatal.

\subsection{PARTICUlaridades DEL PRINCIPIO DE LA AUTONOMIa de LA VOLUNTAD EN ARBITRAJE}

Para Cahali ${ }^{30}$, el uso del arbitraje es voluntario; es la expresión de la libertad de elección de las partes, siendo fundamental la voluntad de los interesados en establecer este método de resolución de conflictos. La autonomía de la voluntad no es sólo un principio básico del arbitraje, sino también la esencia, que da libertad y fuerza al instituto.

Para Beraldo $^{31}$ "la voluntad es la raíz de lo que puede llamarse derecho arbitral", ya que éste sólo existirá si preexiste un acuerdo de arbitraje a opción de las partes en detrimento de la jurisdicción estatal. Morais y Spengler ${ }^{32}$ refuerzan: "El principio de la autonomía de la voluntad constituye la esencia del tribunal arbitral, desde la facultad de disponer de esta nueva alternativa de solución de controversias, cuando la ley lo permite (derechos disponibles), hasta las disposiciones procesales que la regirán".

Además, para que las partes puedan recurrir al arbitraje como medio de resolución de conflictos, estas deben tener capacidad para contratar (capacidad civil) y el litigio debe

\footnotetext{
${ }^{29}$ FORGIONI, Paula. Teoria geral dos contratos empresariais. São Paulo: Revista dos Tribunais, 2018.

${ }^{30}$ CAHALI, Francisco José. Curso de arbitragem. $5^{\text {a }}$ ed. São Paulo: Revista dos Tribunais, 2015.

${ }^{31}$ BERALDO, Leonardo de Faria. Curso de arbitragem de acordo com a Lei 9.307/96. São Paulo: Editora Atlas, 2014.

${ }^{32}$ MORAIS, J. L. B.; SPENGLER, F. M. Mediação e arbitragem. Alternativas à jurisdição. Porto Alegre: Livraria do Advogado, 2019, v.1.
} 
versar sobre derechos estrictamente patrimoniales, excluyendo de la valoración cuestiones de interés estatal, derecho personal, familiar y otros ${ }^{33}$.

Una vez cumplidos estos supuestos, se respeta al máximo la voluntad de las partes en el arbitraje. Inicialmente, como posibilidad de indicar el propio arbitraje como medio de resolución del conflicto, posteriormente como indicación de las cuestiones que componen esta opción, tales como: quiénes y cuántos árbitros serán (directa o indirectamente), cómo se desarrollará el procedimiento arbitral (plazos, lugares, pruebas, restricción para medidas de emergencia, etc.), normas de derecho que pueden aplicarse o incluso la opción por la equidad, principios generales del derecho, costumbres o reglas internacionales de comercio $^{34}$.

Con la misma importancia se hace el análisis del principio kompetenz-kompetenz previsto en el Art. 8, p.u. y Art. 20 de la Ley de Arbitraje, he que ese establece que corresponde al árbitro decidir sobre la validez y eficacia de la convención y del contrato que tiene una cláusula compromisoria.

Esta norma es de fundamental importancia para la institución del arbitraje, ya que, si le correspondiera al poder judicial decidir, en primer lugar, sobre la validez de la cláusula, el inicio del procedimiento de arbitraje se postergaría durante un largo período, y a veces sólo con el fin de retrasar a una de las partes la evasión del cumplimiento de la convención. El principio refuerza así el instituto y, en la medida en que, el riesgo de desalentar la contratación de un arbitraje debido a un posible obstáculo previo que surgirá en el Poder Judicial antes del acuerdo, por maniobra maliciosa de una de las partes ${ }^{35}$.

Cabe mencionar que esta norma elimina del poder judicial la evaluación solamente por un determinado período de tiempo, de modo que la parte que se considera perjudicada puede recurrir a la justicia estatal para que ésta se manifieste, en un momento posterior, sobre posibles nulidades derivadas del arbitraje ${ }^{36}$.

\footnotetext{
${ }^{33}$ CARMONA, Carlos Alberto. Arbitragem e procedimento - comentários sobre a lei 9.307/96. Río de Janeiro: Editorial Atlas, 2004.

${ }^{34}$ CAHALI, Francisco José. Curso de arbitragem. $5^{\text {a }}$ ed. São Paulo: Revista dos Tribunais, 2015.

${ }^{35}$ CAHALI, Francisco José. Curso de arbitragem. $3^{\mathrm{a}}$ ed. São Paulo: Revista dos Tribunais, 2013.

${ }^{36}$ SPENGLER, Fabiana; SPENGLER NETO, Theobaldo (org). Mediação, conciliação e arbtiragem. Rio de Janeiro: Editora FGV, 2016.
} 
Rio de Janeiro. Ano 15. Volume 22. Número 3. Setembro a Dezembro de 2021

Periódico Quadrimestral da Pós-Graduação Stricto Sensu em Direito Processual da UERJ

Patrono: José Carlos Barbosa Moreira (in mem.). ISSN 1982-7636. pp. 122-142 www.redp.uerj.br

El respeto del principio kompetenz-kompetenz es un factor decisivo para asegurar la autonomía de la voluntad de las partes y, por consiguiente, la seguridad jurídica en el uso del instituto de arbitraje. Su estudio es fundamental para comprender las decisiones recientes.

\section{ANÁLISIS DE LAS INTERPRETACIONES JUDICIALES RECIENTES: EL PRINCIPIO DE KOMPETENZ KOMPETENZ COMO GARANTÍA DE LA AUTONOMÍA DE LA VOLUNTAD}

Los juicios recientes son de suma importancia para comprender la viabilidad y la sostenibilidad del arbitraje en territorio brasileño. Aunque el poder legislativo se ha ido movilizando progresivamente para promover el uso del instituto y hoy en día esto es una realidad en las relaciones contractuales y corporativas, los casos prácticos han requerido de los magistrados una apreciación profunda del uso de las cláusulas de arbitraje, especialmente en lo que respecta a la relación entre la autonomía de la voluntad y las presuntas violaciones de los derechos fundamentales y el orden público, ya propugnada por la mirada crítica de Rocha ${ }^{37}$ al abordar las posibles inconstitucionalidades del instituto.

Se retira, desde luego, la posibilidad de utilización compulsoria de arbitraje en las relaciones contractuales con los consumidores, en conformidad con la prohibición expresa del artículo 51, VII del Código de Protección del Consumidor ${ }^{38}$ 39, aunque se respeten los requisitos del artículo 4, párrafo 2 de la Ley de Arbitraje ${ }^{40}$. En una decisión de noviembre del $2019^{41}$ se entendió que la confrontación entre las disposiciones del CDC y la Ley de

\footnotetext{
${ }^{37}$ ROCHA, José de Albuquerque. O direito e a arbitragem: uma avaliação crítica. São Paulo: ed. Atlas, 2008. ${ }^{38}$ Art. 51 - Serán nulas las cláusulas contractuales relativas al suministro de productos y servicios, entre otras: VII - determinar el uso obligatorio del arbitraje.

${ }^{39}$ BRASIL. Lei $n^{\circ}$ 8.078, de 11 de setembro de 1990. Código de defesa e proteção ao consumidor e outras disposições. Disponible en: http://www.planalto.gov.br/ccivil_03/Leis/L8078.htm. Acceso el 26 de enero de 2020

${ }^{40}$ Art. 4 - La cláusula de arbitraje es el acuerdo por el cual las partes en un contrato se comprometen a someter a arbitraje las controversias que puedan surgir en relación con dicho contrato. § 2 En los contratos de adhesión, la cláusula de arbitraje sólo será efectiva si el adherente toma la iniciativa de instituir el arbitraje o está expresamente de acuerdo con su institución, siempre que lo haga por escrito en un documento adjunto o en negrita, con la firma o el visado especialmente para dicha cláusula.

${ }^{41}$ Resp. REsp 1785783 / GO RECURSO ESPECIAL/ 2018/0229630-5, disponible en: (https://ww2.stj.jus.br/processo/revista/inteiroteor/?num_registro=201802296305\&dt_publicacao=07/11/201 9)
} 
Arbitraje "es solamente aparente pues no resiste a la aplicación del principio de especialidad de las normas", siendo la norma de protección a la parte vulnerable pertinente al caso.

En cuanto a la excepción debida al carácter no obligatorio o una posible concordancia del consumidor con la utilización de la cláusula, que ahora configuraría su validez, la magistrada Nancy Andrighi señaló la interpretación del propio tribunal en el sentido de que "el hecho de que el consumidor apele a la justicia tendría el efecto de eliminar la obligación de participar en el procedimiento de arbitraje". En otras palabras, el hecho de recurrir a los tribunales para resolver el conflicto ya demostraría la desconformidad del consumidor con la institución de la cláusula de arbitraje, en la que, aunque hubiera firmado el contrato y cumpliera con todos los requisitos necesarios de la cláusula.

Por lo tanto, no hay mayor expectativa en la consolidación del uso del arbitraje en las relaciones contractuales de naturaleza de consumo debido a sus particularidades y a la presunción de asimetría entre los contratantes. Sin embargo, no hay ningún impedimento para que las partes se pongan de acuerdo sobre el arbitraje en un momento posterior al contrato mediante el compromiso de arbitraje, lo que así, podría caracterizar el uso no obligatorio del instituto.

Por otra parte, en los contratos mercantiles, la lógica interpretativa se ha demostrado diferente. Por ejemplo, la empresa “A” presentó una Acción Declaratoria de Mantenimiento de Contrato con pretensión de reparación de daños y perjuicios contra la empresa "B", derivada de la terminación de una relación contractual de prestación de servicios de transporte. La empresa demandada, en excepción preliminar, alegó la presencia de cláusula compromisoria y la necesaria observación al principio de kompetenz-kompetenz. Tanto en el laudo como en la sentencia, se rechazó la solicitud de la empresa demandante de llevar el litigio al tribunal de arbitraje, ya que se reconoció la vulnerabilidad de la parte demandante debido a la disparidad económica entre las empresas. El demandado presentó Recurso Especial $^{42}$ :

Contrato celebrado entre las partes con una cláusula compromisoria expresa, que establece el arbitraje como instrumento para resolver las controversias derivadas de cualquier disputa o reclamación, el que hace imposible que las partes recurran al Poder Judicial para resolver una

\footnotetext{
${ }^{42}$ En el sistema brasileño el Recurso de Apelación direccionado al Superior Tribunal de Justicia è reconocido como "Recurso Especial" (REsp).
} 
Revista Eletrônica de Direito Processual - REDP.

Rio de Janeiro. Ano 15. Volume 22. Número 3. Setembro a Dezembro de 2021

Periódico Quadrimestral da Pós-Graduação Stricto Sensu em Direito Processual da UERJ

Patrono: José Carlos Barbosa Moreira (in mem.). ISSN 1982-7636. pp. 122-142 www.redp.uerj.br

controversia relativa a su cumplimiento. [...] Por consiguiente, incumbe al tribunal arbitral pronunciarse sobre todas las cuestiones derivadas del contrato, incluidas la existencia, la validez y la eficacia de la cláusula de arbitraje. La vulnerabilidad reconocida en el origen no es causa suficiente para caracterizar las hipótesis de excepción a la cláusula de Kompetenz-Kompetenz. (REsp 1598220 / RN RECURSO ESPECIAL 2016/0115824-0. Relator. Ministro PAULO DE TARSO SANSEVERINO (1144). T3 - TERCERA CLASE. 25/06/2019)

Para el relator de la decisión Paulo de Tarso Severiano: "Habiendo acordado las partes que la resolución de sus conflictos se hará a través de un arbitraje, insertando una cláusula compromisoria en una transacción legal, la autonomía de la voluntad de los contratistas debe ser respetada".

En otras palabras, se trata de una relación contractual de carácter mercantil en que se ha reconocido (y por todos los órganos jurisdiccionales) la vulnerabilidad de la empresa demandante. Como se ha visto, la mitigación de la Teoría Finalista que preveía la aplicación de las normas protectoras de la legislación especial de consumo en estos casos no vinculó la interpretación de los magistrados para relativizar la autonomía de las partes, la consecuente injusticia de las cláusulas contractuales y la remisión a la jurisdicción estatal.

La decisión contrasta con la propia interpretación del tribunal sobre los contratos de consumo, he que presume la asimetría y justifica la vulnerabilidad del consumidor y tiende a reconocer el carácter abusivo y la nulidad de la cláusula compromisoria firmada por ese.

En otro caso, la empresa "A", de nacionalidad brasileña, garante de contratos de préstamo para la financiación de la construcción de centrales termoeléctricas realizados entre una institución financiera alemana y empresas energéticas multinacionales, presentó una Acción de Declaratoria de Falsedad con Exhibición de Documentos, una vez notificada sobre posibilidad de responder por la obligación decurrente del incumplimiento contractual. El demandante alegó haber sido víctima de falsedad material de sus propias firmas presentes en el contrato. Instruyó a la inicial con un dictamen de perito privado que confirmaba la falsedad de las firmas. Además, en el curso de la demanda, la Policía Federal Brasileña habría llevado a cabo inspecciones de los documentos, habiendo concluido que las firmas proporcionadas en el acta de la sesión del Consejo de Administración de la empresa eran inauténticas, momento en que se habrían aprobado las garantías mencionadas. 
Se trata, todavía, de un asunto de orden penal, (por supuesto de orden público) reconocido en el momento anterior a la institución del arbitraje.

La empresa demandada alegó la existencia de cláusula compromisoria en los contratos indicados y la incompetencia del Estado para valorar el hecho. Ahora examinamos los extractos del argumento utilizado por la mayoría de los ministros del Tribunal Superior de Justicia:

Se afirma además que está vigente en la jurisdicción privada el principio básico de la Kompetenz-Kompetenz, consagrado en los artículos 8 y 20 de la Ley de Arbitraje que establece que es el propio árbitro quien decide, con prioridad respecto al juez togado, sobre su competencia para apreciar la existencia, validez o eficacia del contrato que contiene la cláusula compromisoria. Basándose en esta premisa, el Tribunal de Arbitraje demuestra ser el competente para analizar su propia competencia para resolver la controversia. Negar la aplicación del acuerdo de arbitraje significa, en última instancia, violar el principio de autonomía de la voluntad de las partes y la presunción de idoneidad del propio arbitraje, generando inseguridad jurídica. (REsp 1550260 / RS RECURSO ESPECIAL 2014/0205056-2 Relator: Ministro PAULO DE TARSO SANSEVERINO - TERCER CURSO Fecha de la sentencia 12/12/2017. Fecha de publicación/fuente DJe 20/03/2018)

Es evidente que el tribunal reconoció la autonomía de la voluntad de las partes mediante la cláusula de competencia como forma de salvaguardar la seguridad jurídica y la "idoneidad" del instituto de arbitraje. Se puede considerar que la decisión abarca una circunstancia vital para el uso del arbitraje, ya que, en la práctica, trata de desalentar a la parte contraria a la institución del arbitraje a través de cuestiones de orden público como forma de evitar el uso de la jurisdicción paraestatal y de eximirse de las obligaciones asumidas con la cláusula compromisoria.

Por otra parte, se trata de una cuestión de orden público y de derecho indisponible de carácter indelegable por la jurisdicción estatal, ya que tiende a trascender los intereses de las partes. La propia Ley de Arbitraje ${ }^{43}$ reconoce la incompetencia del árbitro para juzgar

\footnotetext{
${ }^{43}$ Art. 1: Las personas con capacidad de contratar podrán recurrir al arbitraje para resolver las controversias relativas a los derechos de propiedad disponibles.
} 
asuntos de esta naturaleza, lo que de hecho fue puesto de relieve por la parte divergente y derrotada de los magistrados.

Efectivamente, para la mayoría y, a pesar de la supuesta falsedad constituir una cuestión de orden público, ésta no resultó ser decisiva para el juicio del caso por la jurisdicción estatal, ni ofreció elementos sólidos para caracterizar la inexistencia o invalidez de la cláusula compromisoria. Correspondía, pues, al árbitro, como "medida mínima de su competencia, reconocer la existencia y la validez del compromiso de arbitraje, que pasa naturalmente por evaluar la santidad de la manifestación de voluntad expresada por las partes, objeto de la propia acción en comentario" 44 .

Además, defendió la posibilidad de ampliar la jurisdicción del árbitro para examinar cuestiones de orden público, como puede verse en los extractos de la decisión:

Es cierto que el arbitraje sólo puede convocarse para resolver cuestiones relacionadas con los derechos de propiedad disponibles (artículo 1 de la Ley $N^{\circ}$ 9306/1996), excluyendo la posibilidad de que las partes confíen a un árbitro la evaluación de los derechos indisponibles, como las cuestiones de estado, los derechos de la personalidad o los relacionados con los intereses de los menores. Esta advertencia se refiere, sin embargo, a la cuestión iniciada por el contrato que se someterá a arbitraje. Nada impide que, una vez establecida la cláusula de arbitraje, se inste al árbitro a enfrentarse a cuestiones de orden público. Esto puede ocurrir, por ejemplo, cuando se alega la incapacidad de la parte para contratar 0 , como en el caso, la falsedad material de la firma lanzada en el contrato. ${ }^{45}$

Por lo tanto, no bastó la tendencia a promover la autonomía de la voluntad de las partes en relación con posibles asuntos penales argüidos antes de la institución del arbitraje, hay una interpretación que otorga al árbitro la facultad de decidir sobre los derechos

Art. 2: El arbitraje puede ser de derecho o de equidad, a discreción de las partes: $§ 1$ Las partes pueden elegir libremente las normas de derecho que se aplicarán en el arbitraje, siempre y cuando no se violen las buenas costumbres y el orden público.

44 Voto del Min. Marco Aurélio Belizze, disponible en: https://ww2.stj.jus.br/processo/revista/documento/mediado/?componente=ATC\&sequencial=79217689\&num _registro $=201402050562 \&$ data $=20180320 \&$ tipo $=3 \&$ formato $=$ PDF.

45 Voto del Ministro Moura Ribeiro, disponible https://ww2.stj.jus.br/processo/revista/documento/mediado/?componente=ATC\&sequencial=78558812\&num _registro $=201402050562 \&$ data $=20180320 \&$ tipo $=3 \&$ formato $=$ PDF. 
indisponibles. Por lo tanto, una vez establecida la cláusula compromisoria, correspondería al árbitro la responsabilidad de analizar todo e cualquier criterio de existencia, eficacia y validez, así como identificar las cuestiones de alcance penal y temas relacionados con la capacidad de las partes sometidas al arbitraje.

\section{CONSIDERACIONES FINALES}

Es notorio que el Estado brasileño se ha esforzado por hacer posible el acceso a la justicia a través de medios alternativos de solución de controversias, especialmente el arbitraje, en vista de la ejecutabilidad de la decisión. Los recientes cambios legislativos refuerzan el interés del legislador por fortalecer la autonomía de la voluntad de las partes y la solidez del acuerdo en las relaciones contractuales en el derecho interno.

De manera convergente, el poder judicial ha fomentado la jurisdicción prima facie del árbitro designado mediante el principio de kompetenz-kompetenz, además de presentar tendencias a ampliar su jurisdicción sobre temas complejos de interés público. Con excepción de las relaciones contractuales de consumo, en que hay que reconocer la existencia de una parte vulnerable - he que ya transborda de legislación proteccionista reforzando el carácter abusivo e la nulidad del acuerdo -, las demás relaciones jurídicas civiles y mercantiles han reconocido la fuerza vinculante de la cláusula compromisoria, aunque se planteen argumentos de orden penal o de derechos indisponibles.

En términos generales, puede concluirse que el estudio y el respecto del principio de la autonomía de la voluntad en las relaciones contractuales en el derecho interno son de fundamental importancia para garantizar el funcionamiento y la seguridad jurídica del arbitraje como alternativa para el acceso a la justicia.

\section{REFERENCIAS:}

ANDRADE, Paula. Congestionamento do poder judiciário cai para 72\% em 2017. Conselho Nacional de Justiça, $2018 . \quad$ Disponible en: <https://www.cnj.jus.br/congestionamento-do-judiciario-cai-para-72-em-2017/>. Acceso el 23 de enero de 2020 
AYOUB, Luiz Roberto. Arbitragem: o acesso à justiça e a eficacia do processo - uma nova proposta - Río de Janeiro: Editora Lemen Juris, 2005.

BERALDO, Leonardo de Faria. Curso de arbitragem de acordo com a Lei 9.307/96. São Paulo: Editora Atlas, 2014.

BRASIL. Lei $n^{o}$ 8.078, de 11 de setembro de 1990. Código de defesa e proteção ao consumidor e outras disposições. Disponible en: http://www.planalto.gov.br/ccivil_03/Leis/L8078.htm. Acceso el 26 de enero de 2020

BRASIL. Congestionamento do Judiciário cai para $72 \%$ em 2017. Conselho Nacional de Justiça, 2018. Disponible en: https://www.cnj.jus.br/congestionamento-dojudiciario-cai-para-72-em-2017/.

BRASIL. Lei 9.307 de 1996. Lei da arbitragem. Diário Oficial da República Federativa do Brasil Gaceta Oficial de la República Federativa del Brasil, Brasilia, DF, 23 de setembro de $1996 . \quad$ Disponible en: <http://www.planalto.gov.br/ccivil_03/leis/19307.htm>. Acceso el 10 de febrero de 2020 .

BRASIL. Lei $n^{\circ}$ 13.966, de 26 de dezembro de 2019. Dispõe sobre o sistema de franquia comercial e revoga a lei No 8.955 de 15 de dezembro de 1994 (Ley de Franquias). Disponible en: <http://www.planalto.gov.br/ccivil_03/_Ato20192022/2019/Lei/L13966.htm\#art9>. Acceso el 11 de febrero de 2020.

BRASIL. Medida provisória 881 de 11 de abril de 2019. Congresso Nacional, Brasilia, DF. Disponible en: < http://www.planalto.gov.br/ccivil_03/_Ato20192022/2019/Exm/Exm-MP-881-19.pdf >. Acceso el 2 de febrero de 2020.

CAHALI, Francisco José. Curso de arbitragem. $3^{\mathrm{a}}$ ed. São Paulo: Revista dos Tribunais, 2013.

CAHALI, Francisco José. Curso de arbitragem. $5^{\text {a }}$ ed. São Paulo: Revista dos Tribunais, 2015 .

CARMONA, Carlos Alberto. Arbitragem e procedimento - comentários sobre a lei 9.307/96. Río de Janeiro: Editorial Atlas, 2004.

COELHO, Fábio Ulhoa. Curso de direito comercial v. III. $15^{\mathrm{a}}$ ed. São Paulo: Editora Saraiva, 2014. 
FORGIONI, Paula. Teoria geral dos contratos empresariais. São Paulo: Revista dos Tribunais, 2018.

GEHLEN, Bernardo Baccon. Princípio da autonomía da vontade nos contratos empresariais de direito nacional e internacional. Santa Cruz do Sul: UNISC, 2019. 57 f. Monografia. Curso de Graduação da Universidade de Santa Cruz do Sul, 2019.

MORAIS, J. L. B.; SPENGLER, F. M. Mediação e arbitragem. Alternativas à jurisdição. Porto Alegre: Livraria do Advogado, 2019, v.1.

REIS, J. R.; DICK, J. H. Direitos Fundamentais: delimitações da sua influência no Direito Privado. Santa Cruz do Sul: Revista do Direito, p. 7-40, 2006.

REIS, Jorge Renato. A função social do contrato e sua efetiva vinculação com as partes contratantes. Santa Cruz do Sul: Revista do Direito, p. 109-139, 2001.

RIZZARDO, Arnaldo. Contratos. $18^{\mathrm{a}}$ ed. Río de Janeiro: Ed. Forense, 2019

ROCHA, José de Albuquerque. O direito e a arbitragem: uma avaliação crítica. São Paulo: ed. Atlas, 2008.

ROSENVALD, Nelson; FARIAS, Cristiano Chaves. Curso de direito civil 4: contratos, teoría geral dos contratos em espécie. São Paulo: Editora Atlas, 2015.

SPENGLER, Fabiana; SPENGLER NETO, Theobaldo (org). Mediação, conciliação $e$ arbtiragem. Rio de Janeiro: Editora FGV, 2016. 